\title{
Geoscience data and derived spatial information: societal impacts and benefits, and relevance to geological surveys and agencies
}

\author{
R.A. Hughes \\ British Geological Survey, Sir Kingsley Dunham Centre, \\ Keyworth, Nottingham, NG25 ORL, United Kingdom
}

\begin{abstract}
Low levels of geospatial literacy and geoscientific understanding mean that basic geological map data are meaningful to, and can therefore be interpreted by, a remarkably small number of people with specialist knowledge and training. Nevertheless geological maps continue to underpin the exploration, exploitation and management of natural resources including fossil fuels, minerals and groundwater. Geological maps can, however, be the essential basis for derived, spatial geoscience information through which complex science relating to societally relevant issues such as geohazards can be communicated meaningfully to the lay person. Such derived spatial geoscience information offers opportunities for geological surveys and agencies to demonstrate societal relevance by creating social and economic benefits.

Producing and delivering such information from complex geoscientific data should therefore be central to the mission of geological surveys and agencies. The pathway is traced from data to information and knowledge of use in decision-making. Societal benefits and impacts are described and quantified using case studies and independent economic impact analysis data.
\end{abstract}

\section{WHO USES GEOLOGICAL MAPS?}

\section{Geospatial literacy}

The ability to understand even simple topographical mapping requires of the user knowledge of fundamental concepts such as scale, azimuthal orientation, elevation, contours and map symbology. Nevertheless, the proportion of the population able to use such topographical mapping is on the rise, at least in the UK. This is due to many factors including the ready availability of online mapping from established providers, the increasingly routine availability and use of GPS satellite positioning and navigation systems, and new initiatives enabled by these technologies (e.g. OpenStreetMap and OpenCycleMap).

Innovative outreach programmes from state topographical mapping agencies such as the UK's Ordnance Survey (OS) also play a part. The OS, for example, provides paper topographical maps free of charge to secondary school pupils (the 11-16 age group) in the UK. With links into the school curriculum it is clear that this initiative is increasing the level of understanding of topographical mapping of children in the UK from all socio-economic backgrounds. 


\section{Geoscientific literacy}

To interpret a geological map requires not only the fundamentals of scale, azimuthal orientation, and elevation, but also familiarity with highly specialised concepts including stratigraphy and stratigraphical relationships, geological structure, complex symbology and an ability to visualise structural, stratigraphical and lithodemic relationships in three dimensions.

So what proportion of a population has the necessary skills and knowledge to both produce and interpret geological map data to a professional standard? In trying to answer this question it is useful to consider a few national examples, and necessary also to accept a basic assumption that to interpret (and produce) a geological map to a professional standard requires graduate level geoscience knowledge and skills.

Natural resource exploration and production make a major contribution to the Canadian economy. Between May 2008 and May 2009 oil, gas and mineral production were valued at CN \$49.9 Billion or 4.2\% of GDP (Statistics Canada), while during the same period exploration investment was estimated at CN \$ 2.8 Billion (The Northern Miner 2009). Canada’s population is approximately 33 million, and in 2008 Canadian universities produced around 1,200 geoscience graduates. In 2008, therefore, a paltry additional $0.004 \%$ of the Canadian population developed the expertise to interpret a geological map to acceptable professional standards.

In the UK, whose economy is less dependent upon resource exploration and production but to which geoscience is equally important for other environmental management reasons, approximately 1,300 earth sciences (geology, environmental sciences etc.) students graduated in 2008. With a national population of approximately 60 million this means that in 2008 an extra $0.002 \%$ of the UK population developed the expertise to interpret a geological map to professional standards. Whatever the errors in these crude figures, it is beyond dispute that the proportions of the populations of these countries able to interpret geological maps are extremely low.

A further relevant trend lies in the numbers of geoscience graduates that do not pursue careers in geoscience, and whose essential skills in producing and interpreting geological maps are effectively lost to their national economies. The American Geological Institute (2009), for example, reported that less that $13 \%$ of the approximately 6,000 new US geoscience bachelor's majors graduating in the fall of 2008 will ever work professionally in geoscience. Similarly (but slightly less pessimistically) of the approximately 1,300 earth science graduates produced annually in the UK, only half of those will find their first employment in the earth sciences.

It can be concluded, therefore, that although levels of topographical mapping literacy and use are increasing (at least in the UK), the proportion of the population of major nations that can produce and interpret basic geological mapping to professional standards is extraordinarily small. Furthermore, in the cases of the UK and US in 2008 at least half (and in the US significantly more) of those graduating from universities with the appropriate skills are lost to 
the profession, either through deliberate career choice decisions or because of the unavailability of geoscience employment.

The taxes and royalty contributions of the extractive industries to national economies can be huge. Since these industries are reliant on basic geological map data it follows that the underpinning contribution of such data to the development and productivity of resourcedependent economies is also very great.

However, taking into account the extremely low levels of geospatial and geoscientific literacy described above it is evident that basic geological map data are largely meaningless to the overwhelming proportion of populations who lack the skills and knowledge required to interpret such data. There are, however, very real and quantifiable social and economic impacts and benefits in high resolution spatial geoscience data-sets that can be derived from basic geological map data.

\section{DERIVED SPATIAL GEOSCIENCE INFORMATION}

Geological surveys and environmental agencies in tectonically and volcanically active parts of the globe have for many years been using primary geological mapping as the baseline data-set from which are derived geohazard maps for use in civil planning, emergency planning and response, and engineering design. The need to understand and mitigate the potential hazards of earthquakes in particular has focused the efforts of agencies on producing geospatial information that can be used by non-specialists. Examples include seismicity, ground shaking, induced landslide potential and both probabilistic and deterministic liquefaction potential maps developed specifically for urban planning and development, disaster mitigation and response planning (see, for example, USGS 2009).

While tsunami hazard potential maps for some parts of the Pacific Coast of North America have existed for many years, one consequence of the devastating Indian Ocean tsunami of December $26^{\text {th }} 2005$ was the focusing of research effort on mapping zones of tsunami hazard along previously poorly understood populous coastlines. As a result, tsunami hazard maps (at least at low resolutions) now exist for most of the world's populous coastlines including areas where tsunami hazard potential is generally regarded as low (e.g. Schmidt-Thomé 2006). Similarly, pyroclastic flow and mud-flow hazard potential maps are available for many of the world's volcanoes that are located in populous areas (see, for example, Orsi et al., 2004).

While large parts of the earth's surface are seismically relatively inactive and distant from active volcanic sources, they may still be vulnerable to more insidious but nevertheless potentially damaging geological hazards. As custodians of unique geoscience data holdings and owners of sometimes unique in-house expertise, there are real opportunities for geological surveys and agencies to demonstrate societal relevance and generate economic benefits by producing geospatial information characterising vulnerability to these hazards. 


\section{From data to information and knowledge for decision-making - the knowledge transfer dimension}

In 2001 the British Geological Survey (BGS) launched the world's first national digital vectorised and attributed geological map at the 1:50,000 scale (DiGMapGB, see BGS 2009a). In 2003 the BGS initiated a programme with the specific objective of using the DiGMapGB digital geological map data as the basis from which to produce societally useful, derivative national geohazard potential information. Within this programme the BGS has since 2003 produced, and annually updated, national geohazard potential data-sets including ground stability, natural radon potential, flooding (groundwater, coastal and riverine), permeability, non-coal mining, and potentially harmful elements in soils. Significantly for the lay=person this high resolution geospatial information can be interrogated on a location- or propertyspecific basis, or by postal code (zip code).

The BGS national ground stability data-set (GeoSure, Figure 1, see also BGS 2009b), for example, is multi-layer geospatial information (i.e. a 'GIS data-set') that gives indicative hazard potential values for six shallow geohazards, namely swelling and shrinking clays, soluble rocks, landslides, compressible rocks, collapsible rocks and unconsolidated running sands. First launched in 2003 it is now widely used by both the public and commercial sectors in the UK, in property-specific searches as a preliminary to property sale/purchase transactions and by operators of major infrastructure such as highway and railway networks. GeoSure is now also used by major UK insurers in setting premiums charges for buildings insurance.

Effective knowledge transfer is integral to the success of such geoscience spatial information, enabling them to be used by lay persons with no specialist geoscience knowledge or understanding. The GeoSure landslide hazard potential layer, for example, is produced by multi-parameter analysis with expert knowledge and validation (Table 1). However, those parameters, data and expertise are translated into information expressed in plain English so that complex science can be used as a basis for decision-making by unqualified persons, so increasing the reach, value and impact of the science.

The information can be delivered to the private user on a location- or property-specific basis, or by postal code (zip code). The BGS offers its own such site-specific reporting information service (GeoReports, BGS 2009b), or the user can purchase the same BGS information supplied by one of many private sector 'value-added re-sellers'.

\begin{tabular}{|l|l|}
\hline Data sources and parameters & Information provided for decision making \\
\hline - Lithology & $\begin{array}{l}\text { 'High hazard potential: slope instability problems almost } \\
\text { certainly present and may be active. Significant constraint } \\
\text { on land-use.' }\end{array}$ \\
- Structure & \\
\hline
\end{tabular}


- $\quad$ Porosity, permeability

- Groundwater, natural springs

- Digital terrain models

- Slope angle and class

- BGS national landslide database

'Low hazard potential: slope instability problems are not believed to occur but consideration should be given to potential problems of adjacent areas impacting on the site'

- Expert and GIS validation processes

Table 1. From data to information; the BGS GeoSure landslide hazard potential data-set source data and information provided to users.

\section{Economic benefits of derived geoscience spatial information}

In 2006 the BGS GeoSure natural ground stability hazard potential information was used as a case study by the economists PricewaterhouseCoopers (PwC) in an investigation commissioned by the BGS's parent body, the Natural Environment Research Council (NERC), into the economic benefit of environmental research (Natural Environment Research Council, 2006). PwC concluded the following:

- By using this information decision-takers are empowered to make better informed decisions, and can avoid future costs and prevent loss of investment by avoiding or mitigating subsidence incidents.

- BGS information on subsidence risk, provided at postcode and household level, is 'accurate and relevant to user needs', responsive to climate change impacts, and 'meets the needs of the information age'.

- By using this information financial and social costs can be avoided through avoiding investing in areas at risk of subsidence, or taking pre-emptive action and mitigating subsidence.

- Using this information created wider societal benefits including avoidance of stress, injury and disruption associated with loss of property.

Noting that the annual cost of subsidence to the UK insurance industry is c. $£ 300$ Million, PwC concluded that use of the BGS ground stability information could save UK insurers between $£ 70$ Million - £270 Million in reduced payouts between 2006 and 2030.

The BGS-Health Protection Agency natural radon hazard potential information for England and Wales was launched in 2007 (see Miles et al., 2007). This high resolution spatial information (see also BGS 2007) was produced using a methodology that combines empirical radon measurements with digital geology (Miles and Appleton 2005) and can be interrogated on a property- or location-specific basis. Property owners can use the information to find out indicative natural radon potential levels at their properties or locations (see Figure 2), and to 
decide on remedial action if necessary. Similarly, builders and developers of new homes and commercial premises can factor the same information into the designs of new buildings to mitigate the effects of natural radon.

Exposure to indoor radon is the largest contributor to the radiation exposure of the population (Miles and Appleton 2005). The UK Health Protection Agency estimates that over 1,000 persons die each year in England and Wales due to lung cancers caused by natural radon (Dr Jon Miles, HPA, personal communication 2008). This incidence may increase significantly when combined with other carcinogens such as tobacco-smoking. In many parts of the world natural radon almost certainly causes more deaths than any other environmental hazard. Unlike the BGS ground stability information the BGS-HPA natural radon potential information has not yet been subject to independent economic impact analysis. However, it seems highly likely that such an analysis would conclude that use of the information could lead to the avoidance of a significant number of potentially fatal lung cancers each year.

\section{SOCIETALLY RELEVANT GEOSCIENCE DATA AND THE FUTURE OF GEOLOGICAL SURVEYS AND AGENCIES}

State budgets for many geological surveys and agencies are under severe downward pressure. While basic geological map data continue to underpin the exploitation and management of natural resources, beyond these essential applications they offer little value to wider society in which there are extremely low levels of geoscientific literacy. There are, however, great and largely untapped - opportunities for all geological surveys and agencies to demonstrate their relevance to governments and their wider populations by generating geoscience information with broad societal reach that can yield real and quantifiable social and economic benefits.

The UK government has introduced policies (Research Councils UK, 2007) that put a clear expectation upon public sector research to generate significant increases in the social and economic impacts and benefits of their research programmes. It is not known if similar farsighted policies exist in other countries. However, by virtue of their unique assets of expertise and national data holdings, geological surveys and agencies are extremely well-placed to deliver socio-economic benefits through relevant geoscience information that can be used to support informed decision-making across all sectors of society, so serving the objectives and needs of governments, society and agencies alike. Looking to the future geological surveys and agencies should respond to societal challenges by making the provision of such information central to their missions.

\section{Acknowledgements}

Topographical data in the figures is reproduced with the permission of the Ordnance Survey of Great Britain. 


\section{REFERENCES CITED}

American Geological Institute, 2009. Status of the Geoscience Workforce 2009. Available from www.agiweb.org/workforce.

British Geological Survey, 2007. BGS-Health Protection Agency Radon Potential Data-set. http://www.bgs.ac.uk/radon/hpa-bgs.html.

British Geological Survey, 2009a. DiGMapGB digital geological map of Great Britain. http://www.bgs.ac.uk/products/digitalmaps/digmapgb.html.

British Geological Survey, 2009b. GeoReports. http://shop.bgs.ac.uk/GeoReports/.

Miles, J.H.C. and Appleton, J.D., 2005. Mapping variation in radon potential both between and within geological units. Journal of Radiological Protection, 25 (2005) 257-276.

Miles, J.H.C., Appleton, J.D., Rees, D.M., Green, B.M.R., Adlam, K.A.M., and Myers, A.H., 2007. Indicative Atlas of Radon in England and Wales. Health Protection Agency, Didcot, Oxfordshire, United Kingdom. ISBN 978-0-85951-608-2.

Natural Environment Research Council, 2006. Economic benefit of environmental science. www.nerc.ac.uk/publications/corporate/economic.asp.

OpenCycleMap, www.opencyclemap.org/.

OpenStreetMap, www.openstreetmap.org/.

Orsi, G., Vito, M., and Isaia, R., 2004. Volcanic hazard assessment at the restless Campi Flegrei caldera. Bulletin of Volcanology, 66, p. 514-530.

Research Councils UK, 2007. Increasing the economic impact of the research councils. www.rcuk.ac.uk/innovation/impact/default.htm.

Schmidt-Thomé, P., 2006. The spatial effects and management of natural and technological hazards in Europe. European Spatial Planning Observation Network, 197 p.

Statistics Canada. www.statcan.gc.ca/daily-quotidien/090731/t090731a1-eng.htm.

The Northern Miner, 2009. June 1-7, 95(15), p1-2.

USGS, 2009. Reducing hazards in the Central and Eastern U.S. Reports and maps downloadable from http://earthquake.usgs.gov/regional/ceus/index.php. 
Figure 1. Left GeoSure landslide hazard potential derivative layer; copyright BGS (NERC). Right GeoSure swell-shrink clay hazard potential derivative layer; copyright BGS (NERC).

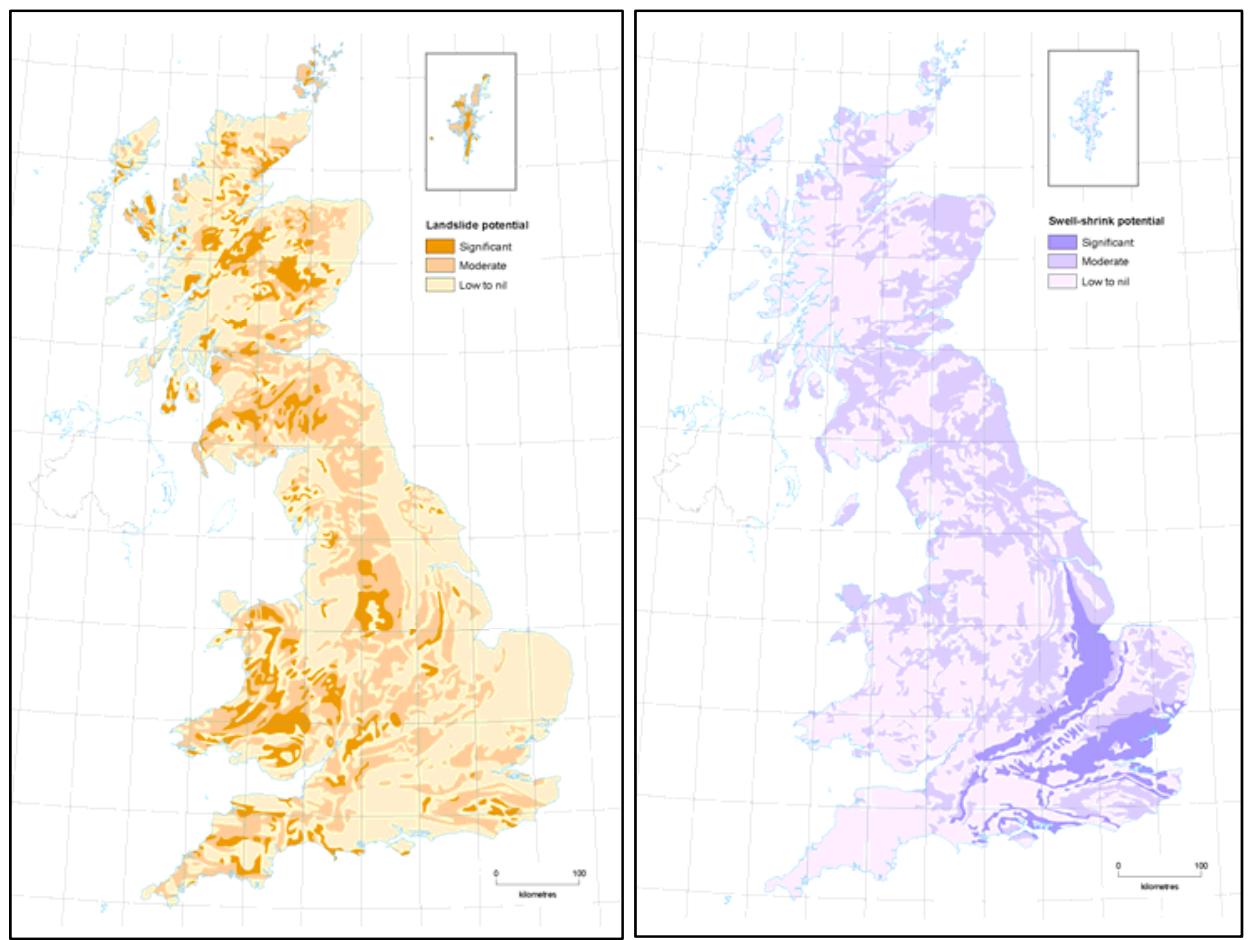


Figure 2: Natural radon hazard potential data-set for part of south-west England. Copyright British Geological Survey (NERC) and Health Protection Agency.

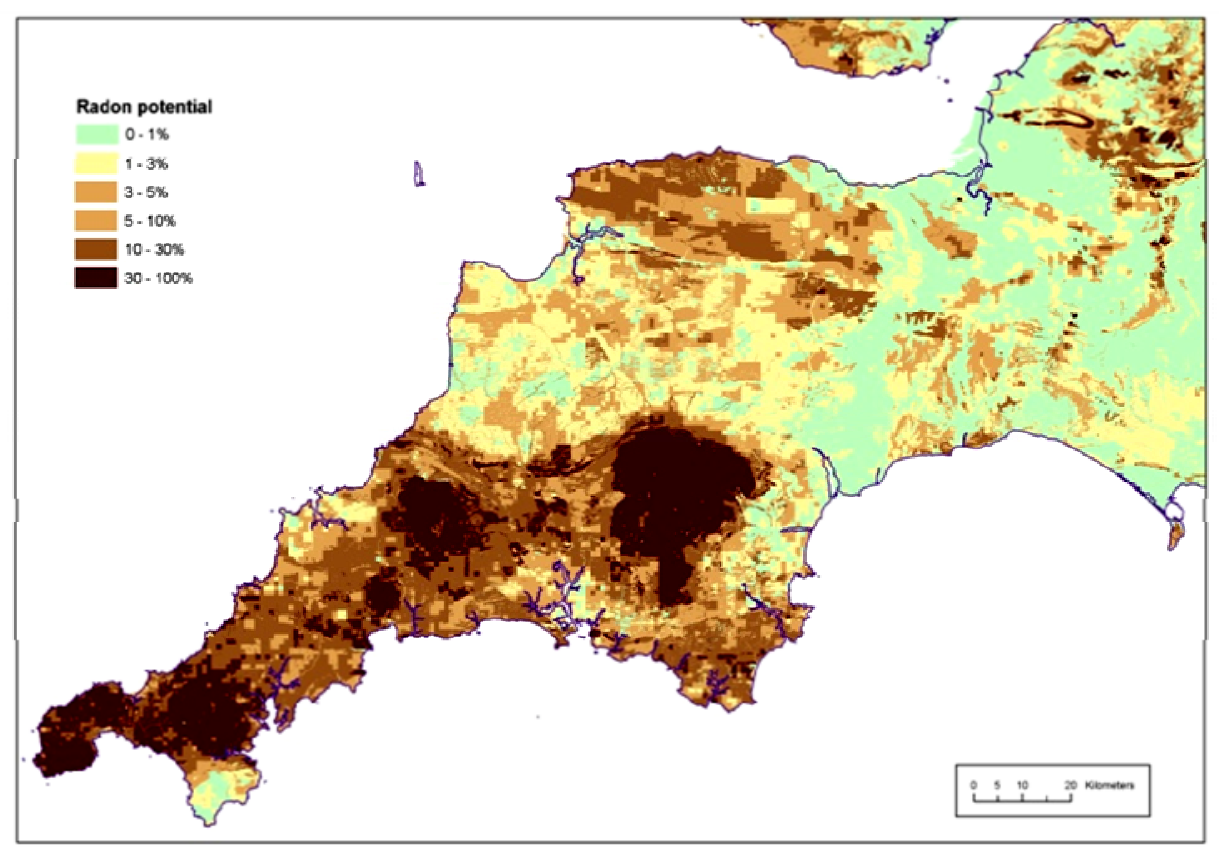

